\title{
Design optimization of the desalination process at Jebel Ali plant in the United Arab Emirates
}

\author{
H. Mashmoushy \\ Department of Mechanical Engineering, Beirut Arab University (BAU), \\ Lebanon
}

\begin{abstract}
The recent advancement of the United Arab Emirates (UAE) has led to a nationwide increase in water consumption. Statistics have shown that roughly $98 \%$ of water consumed in the UAE comes from desalination, due to lack of fresh water sources. In desalination plants the most widely used technique is the Multi-Stage Flash (MSF) Distillation. In this study, condenser tubes have been analyzed with emphasis made on the Jebel Ali Desalination Plant (Dubai). Elliptical tubes have been proposed as a superior alternative to conventional circular tubes, due to their increased surface (heat transfer) area to cross-section area ratio. Mathematical and CFD models were developed to verify and validate these results. Elliptical tubes of $(22.4,9.0) \mathrm{mm}$ were established as the optimum dimensions. Consequently, the thermal efficiency of the MSF cycle was improved by $2.3 \%$, resulting in energy savings of $5429440 \mathrm{~kJ} / \mathrm{hr}$.

Keywords: desalination, condenser tubes, thermal, distillation, multi stage flash, optimization, seawater.
\end{abstract}

\section{Introduction}

There are vast amount of water reserves pinned beneath the Earth's surface. Akili et al. [1] found that as those water reserves are extremely deep, it is exceedingly difficult to be extracted via economically efficient means. Therefore, large scale desalination plants have been set up all over the globe to sustain the growth of the world's population and economy.

In the U.A.E, around $98 \%$ of the water consumed comes from the desalination of seawater from the Arabian Sea, since natural sources for water are extremely limited (Sommariva and Syambabu [2]). Currently there are 30 
desalination plants operating in the U.A.E with a capacity of 1.3 billion cubic meters per year. However, the demand for water is projected to reach around 5 to 7 billion cubic meters by 2020 (Dasari [3]).

There are two different types of thermal distillation processes namely, Multiple Effect Distillation (MED) and Multi Stage Flash (MSF) distillation. The process used in the Jebel Ali desalination plant is the (MSF) Distillation and is a popular choice in the Middle East region $[4,5]$. The desalination unit runs in cogeneration with the Jebel Ali Power Station as low-grade (waste) steam from the adjacent power station is utilised to preheat the water for distillation, thus reducing the thermal energy required in the brine heater. Detailed studies, further analysis and design optimization of this particular process form the core of this paper.

\subsection{Multi-stage flash (MSF) distillation}

In MSF distillation, the seawater is evaporated by lowering the pressure rather than the conventional method of raising the temperature, hence, this process relies on regenerative heating [5]. The Jebel Ali desalination plant consists of four stations, namely, D, E, G, K and L with 7, 4, 8, 4 and 8 units respectively, making a grand total of 23 units. Waste heat from the steam turbine exhaust of the neighbouring power station, is used to preheat the condenser tubes located in the MSF unit's brine heater, which as a result heat the feed water (seawater). The heated seawater is then passed into a low pressure chamber where it instantaneously vaporizes into steam. The steam is then condensed on contact with the condenser tubes which are cooled by the incoming sea water flowing towards the brine heater. Fig. 1, created using Solid Edge V20, displays the side and isometric view of a single MSF unit with 3 stages.

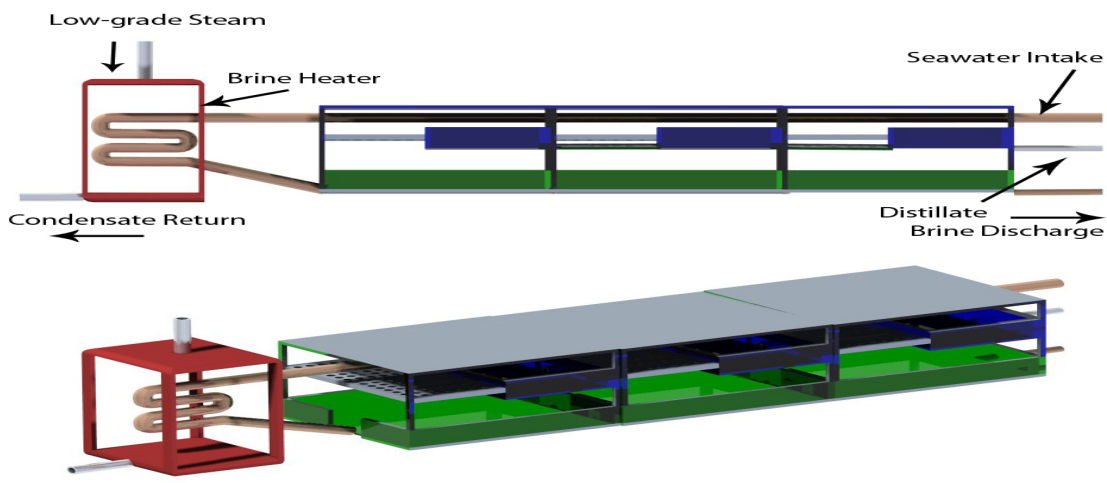

Figure 1: $\quad$ Side (top) and isometric (bottom) view of three stages MSF unit. 
Therefore, the incoming feed water warms up hence lowering the thermal energy required in the brine heater. In the actual process, a mere percentage of water is vaporized (flashed) into steam, as it is dependent on the ambient pressure; and rapid vaporization causes the water temperature to fall below its boiling point. Hence, to improve the efficiency of the cycle, flash distillation makes use of multiple stages in series of increasingly lower pressures which allow the seawater to flow from one stage to the next whilst repeatedly flashing without any additional heat [5]. Within a single MSF unit presented in figures 1 and 2, some of the most notable components include (El-Dessouky et al. [6, 7]):

- Submerged Orifice - to control the flow rate of the brine across the stages.

- Venting Line - Provides an escape for the non-condensable gases (NCs) such as $\mathrm{CO}_{2}$ that are formed during the flashing process. It is critical for a MSF unit to have proper ventilation in the flashing chamber.

- Demister - used to reduce the amount of brine droplets in the flashed vapour. Not only this reduces the salinity of the vapour, but also reduces the scale formation on the outside of the condenser tubes. This phenomenon is known as Vapour Side Corrosion (VPS).

Additional components in a MSF desalination plant consist of pre-treatment of the feed water streams. The treatment for the intake seawater is only set to screening and filtering. However, the treatment for the feed seawater, running in the condenser tubes, is much more elaborate. This includes the de-aeration and addition of antiscalants to control the scale formation (Helal et al. [8-10]). The product rate is highly dependent on the number of stages which is directly associated with the MSF plant finances. An increase in the number of stages increases the heat transfer area improving efficiency, however, it drastically escalates the costs. However, there is a limit to the number of stages as the thermal efficiency of a MSF plant is dependent upon the difference between the brine heater and the final condenser at the opposite side of the plant.

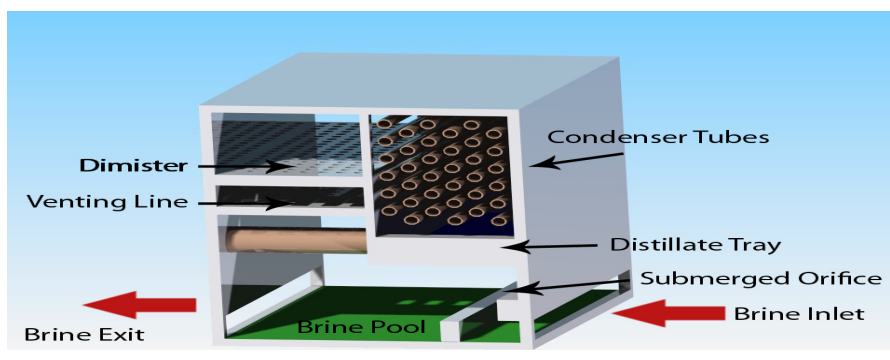

Figure 2: $\quad$ Major components of a single MSF unit.

The Jebel Ali Desalination Plant (E Station) operates at a Top Brine Temperature (TBT) of $110^{\circ} \mathrm{C}$ with a total of 19 stages. Stages $1-16$ are 'heat recovery' whereas stages 17-19 are 'heat rejection'. Increasing the temperature beyond $120^{\circ} \mathrm{C}$ increases the thermal efficiency but also drastically escalates the prospective of harmful scale formation, leading to deterioration of metal surfaces as they are in direct contact with the seawater. Scale formation can be countered 
by demisters, which are integrated into the system to diminish the amount of entrained brine droplets that are carried in the flashed vapour (El-Naas et al. [11]). Also, an excessive quantity of entrained brine could result in high salinity of the produced water (Mohameda et al. [12]).

\subsection{Objective}

The condenser tubes play a substantial part in the successful operation of a MSF cycle. In this paper conventional circular condenser tubes were substituted with elliptical ones. The higher heat-transfer area (surface area) accessible with the same cross-section improved the thermal efficiency of the cycle. This was achieved by carrying out a CFD analysis and developing a mathematical model, using Log Mean Temperature Difference (LMTD) approach. The outcomes of the two models were then validated.

\section{Mathematical model}

\subsection{Log mean temperature difference (LMTD)}

Hot vapour hits the external surfaces of the condenser tubes, where cooler seawater is flowing inside them. Not only does the vapour condense via contact with the tubes, but the seawater within the tubes is preheated as well. Hence, this is modelled as a heat exchanger, specifically of the cross flow type. The (LMTD) approach was used to develop the mathematical model. The rate of heat transfer $(\dot{Q})$ is determined from the following thermodynamic equation:

$$
\dot{Q}=\dot{m} c_{p}\left(t_{2}-t_{1}\right)
$$

Due to heat transfer, the temperature difference along the length of the condenser tubes is not uniform. In reality the temperature change is logarithmic, therefore, LMTD is introduced and is evaluated by the following equation:

$$
\Delta T_{l m}=\frac{\Delta T_{1}-\Delta T_{2}}{\ln \left(T_{1} / T_{2}\right)}
$$

where:

$$
\begin{aligned}
& \Delta T_{1}=T_{h i}-T_{c o} \\
& \Delta T_{2}=T_{h o}-T_{c i}
\end{aligned}
$$

The surface area of the circular tubes is:

$$
A=n \pi D l
$$

Once $\dot{Q}, \mathrm{~A}$, and $\mathrm{T}_{1 \mathrm{~m}}$ have been calculated, the overall heat transfer coefficient, $\mathrm{U}$, is determined from the following equation:

$$
\dot{Q}=U A F \Delta T_{l m}
$$


The correction factor, F, was read from the Bowman, Mueller and Nagle chart. Rearranging equation (6) yields:

$$
U=\frac{\dot{Q}}{A F \Delta T_{l m}}
$$

To determine the new dimensions for the elliptical tubes arrangement, several reasonable values for $\dot{Q}$ were estimated. The above equations were re-applied to determine the new value for the total surface area. It is important to note that the aim is to increase the total surface area whilst keeping the cross-sectional area constant. This is because, if the cross-sectional area is modified, then the mass flow rate of the cycle is altered too and hence the output. The reasoning behind this approach is that the elliptical tubes can be seamlessly integrated into the current design and operation of the Jebel Ali Desalination Plant.

The total surface area of the elliptical tubes is calculated from the following equation:

$$
A_{e}=2 \pi n l \sqrt{\frac{a^{2}+b^{2}}{2}}
$$

Once the desired total surface area for the elliptical tubes is recognized, equation (8) was used to identify the major (a) and minor (b) axis for the elliptical tubes profile. Consequently, the optimum dimensions for the elliptical profile were selected.

\subsection{Assumptions}

In order to successfully model the condenser tubes as a cross-flow heat exchanger, the LMTD approach as stated in [13] was adopted.

\section{Jebel Ali desalination plant specification and data}

The data shown in tables 1 and 2 were provided by the Jebel Ali Power Station and Desalination Plant for the 'E' station.

Table 1: Jebel Ali desalination plant specifications for ' $E$ ' station.

\begin{tabular}{ll}
\hline Characteristic & Value \\
\hline Top Brine Temperature (TBT) & $110^{\circ} \mathrm{C}$ \\
Number of Heat Recovery and rejection Stages & 16 and 3 \\
Brine Heater & $1(2$ multi-pass $)$ \\
Mass flow rate $(\mathrm{kg} / \mathrm{s})$ & 3948 \\
Number of tubes & 387 \\
\hline
\end{tabular}

Table 2: $\quad$ Operating conditions in summer for first MSF stage.

\begin{tabular}{ll}
\hline Property & Temperature (K) \\
\hline Seawater Inlet and outlet & 325.0 and 328.3 \\
Vapour Inlet and outlet & 331.4 and 329.9 \\
\hline
\end{tabular}


Referring to table 3 , the mean temperature change across a stage was calculated as $3.23 \mathrm{~K}$. The data in table 4 has been provided by Jebel Ali Desalination Plant showcasing the heat balance for the ' $E$ ' station.

Table 3: Data of increase in temperature change across each stage.

\begin{tabular}{cccc}
\hline Stage & Temperature $\left({ }^{\circ} \mathrm{C}\right)$ & Temperature $(\mathrm{K})$ & Temp. Change \\
\hline 1 & 100.8 & 373.8 & 3.0 \\
2 & 97.8 & 370.8 & 3.0 \\
3 & 94.7 & 367.7 & 3.1 \\
- & - & - & - \\
15 & 55.3 & 328.3 & 3.2 \\
16 & 52.0 & 325.0 & 3.3 \\
\hline
\end{tabular}

Table 4: $\quad$ Data for heat balance of ' $E$ ' station.

\begin{tabular}{llll}
\hline & $\begin{array}{c}\text { Heat input } \\
(\mathrm{kJ} / \mathrm{hr})\end{array}$ & & $\begin{array}{c}\text { Heat output } \\
(\mathrm{kJ} / \mathrm{hr})\end{array}$ \\
\hline Steam & 361776783 & Product & 276562607 \\
Feed & 765163100 & Cooling Water & 1450919031 \\
Cooling Water & 1109671792 & Losses & 11067998 \\
Total & 2236611675 & Total & 1738549636 \\
\hline
\end{tabular}

\section{Computational fluid dynamics (CFD) analysis}

A CFD model was developed to verify the results attained by the mathematical model. To accomplish the task, a CFD model of the current circular tubes was developed to serve as the benchmark. Furthermore, another CFD model was setup by using the elliptical tubes configuration and the results were compared. The existing setup of the Jebel Ali Desalination Plant houses 387 condenser tubes. The model was developed whilst having the same cross-sectional to surface area ratio as of the original tubes.

\section{Geometry modelling and meshing}

Gambit version 2.3.16 was used to develop the 3D geometry and meshing for both the CFD models. With reference to fig. 3, the mesh elements were selected as Tet/Hybrid and the spacing for the tubes and outer wall was chosen as 50 and 75 respectively. The continuum for the inside of the condenser tubes was set as water while the annulus surrounding it was set as water-vapour. 


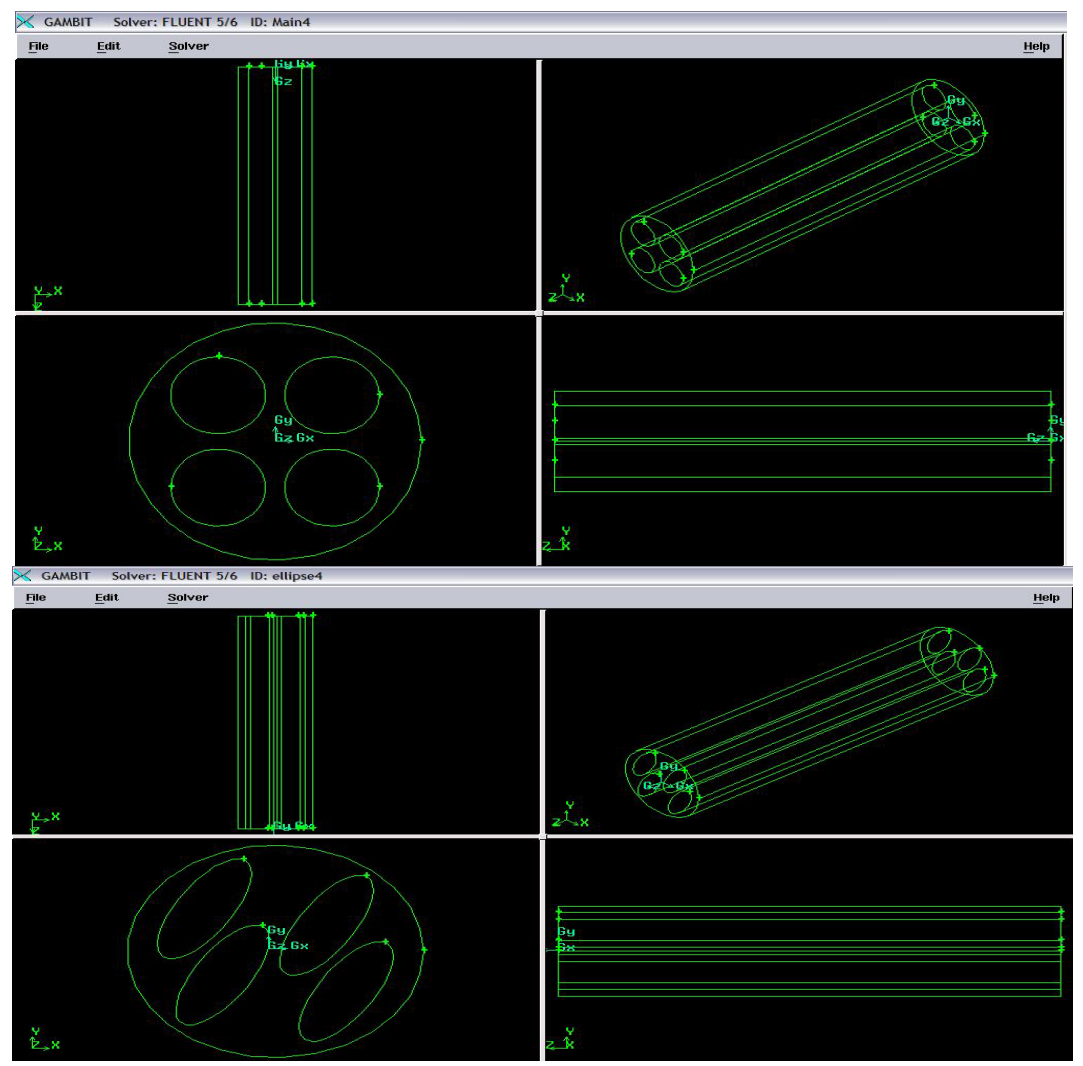

Figure 3: Gambit geometry for circular (top) and elliptical (bottom) tubes.

\section{CFD applications}

CFD analysis was carried out using ANSYS FLUENT 12.1. The code comprises Semi-Implicit Pressure Linked (SIMPLE) algorithms. The geometry made in Gambit was imported into ANSYS FLUENT. The standard k-epsilon model, with default values, was preferred as the viscous model. The energy equation was turned on to enable the input of the temperature values. The operating conditions, as shown in table 2, served as the boundary conditions. Materials for the condenser tubes and outer wall were set as cupronickel (copper-nickel alloy) and stainless steel respectively. For all the walls in the geometry, the tube thickness was selected as $0.005 \mathrm{~m}$ with the shell conduction option enabled. The solution was initialized from the velocity inlet and then run for 1000 iterations until it converged. Initially, the CFD analysis was performed for the circular tubes to serve as the benchmark. Later on, CFD analysis was carried out for the elliptical tubes with the dimensions obtained through the mathematical model. Both CFD models can be used to alter other parameters such as type of material, temperatures (boundary conditions), and thickness of the tubes. 


\section{Results}

The post-processing tool of ANSYS FLUID DYNAMICS was used and figures 4 and 5 were produced to show the temperature contours obtained for the circular and elliptical condenser tubes respectively.

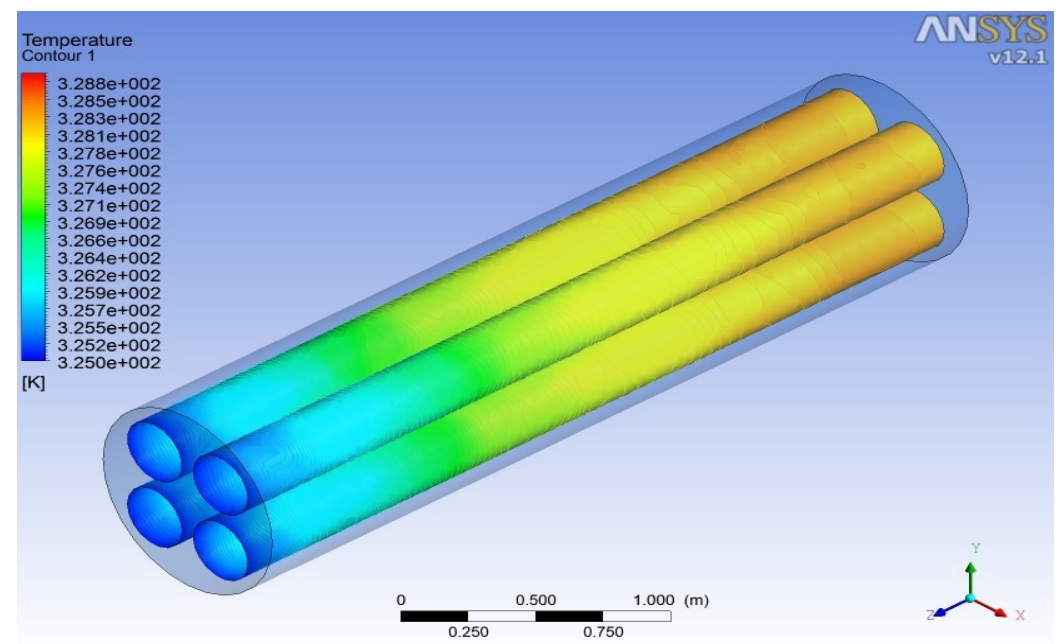

Figure 4: The temperature contour of the Circular tubes.

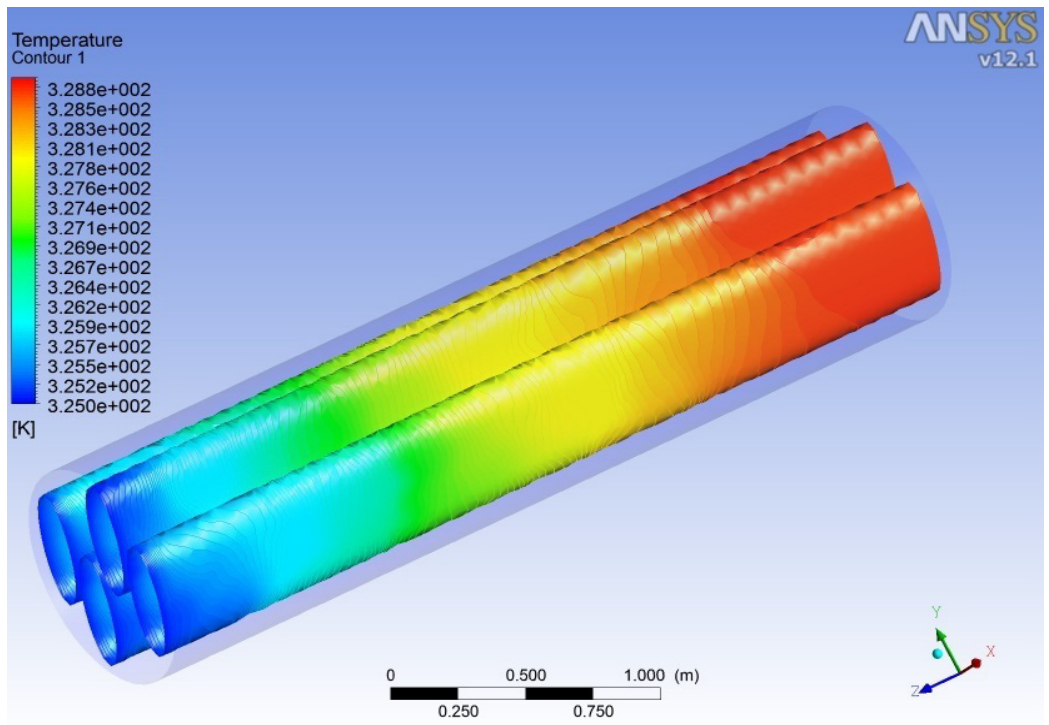

Figure 5: The temperature contour of the Elliptical tubes. 


\section{Theory and calculation}

The heat transfer rate for the original circular tubes is calculated using equation (1) by introducing the operating conditions (presented in table 1) of the first stage of the MFS cycle:

$$
\dot{Q}=\dot{m} c_{p}\left(t_{2}-t_{1}\right) \quad \Rightarrow \dot{Q}=3948 \times 4.18 \times(328.3-325)=54458.71 k
$$

The log mean temperature difference for the same conditions is:

$$
\Delta T_{l m}=\frac{\Delta T_{1}-\Delta T_{2}}{\ln \left(T_{1} / T_{2}\right)} \Rightarrow \Delta T_{l m}=\frac{3.1-4.9}{\ln (3.1 / 4.9)} \Rightarrow \Delta T_{l m}=3.93
$$

The total surface area of the circular condenser tubes is: $A_{c}=n \pi D l$

$$
A_{c}=387 \times \pi \times 0.02975 \times 3.61=130.6 \mathrm{~m}^{2}
$$

The correction factor obtained from the Bowman, Mueller and Nagle chart has been 0.96 . Therefore, the overall heat transfer coefficient using equation (7) is:

$$
U=\frac{54458.712}{130.6 \times 0.97 \times 3.93}=110.525 \mathrm{kw} / \mathrm{m}^{2}
$$

A 15\% increase for the value of $\mathrm{Q}$ was found as a reasonable improvement by using the elliptical tubes configuration:

$$
\dot{Q}=1.15 \times 54458.712 \mathrm{~kW}=62627.50 \mathrm{~kW}
$$

Equation (1) is rearranged to determine the new seawater outlet temperature as:

$$
\dot{Q}=\dot{m} c_{p}\left(t_{2}-t_{1}\right) \Rightarrow \frac{\dot{Q}}{\dot{m} c_{p}}+t_{1}=t_{2} \Rightarrow \frac{62627.505}{3948 \times 4.18}+325=t_{2} \Rightarrow t_{2}=328.8 \mathrm{~K}
$$

The new log mean temperature difference is:

$$
\Delta T_{l m}=\frac{\Delta T_{1}-\Delta T_{2}}{\ln \left(T_{1} / T_{2}\right)}=\frac{2.6-4.9}{\ln (2.6 / 4.9)}=3.63 \mathrm{~K}
$$

The correction factor had a mere increase from 0.96 to 0.97 . Equation (6) was rearranged to determine the surface area (for the elliptical tubes) with the $15 \%$ increase in Q applied.

$$
A_{e}=\frac{\dot{Q}}{U F \Delta T_{l m}}=\frac{62627.505}{110.525 \times 0.97 \times 3.63}=160.93 \mathrm{~m}^{2}
$$

Using the new surface area, the dimensions of the elliptical tubes is thus identified:

$$
A_{e}=2 \pi n l \sqrt{\frac{a^{2}+b^{2}}{2}} \Rightarrow 160.93=2 \pi \times 387 \times 3.61 \sqrt{\frac{a^{2}+b^{2}}{2}}
$$


The above equation consists of two unknowns (variables). Several iterative steps were undertaken to identify the combinations for the major and minor axis for the elliptical profile. The list of dimensions that satisfy the above equation is shown in table 5. The respective total cross-sectional area and surface area are listed alongside.

Table 5: $\quad$ List of combinations of axis for the elliptical profile.

\begin{tabular}{cccc}
\hline $\begin{array}{c}\text { Major Axis } \\
(\mathrm{mm})\end{array}$ & $\begin{array}{c}\text { Minor } \\
\text { Axis }(\mathrm{mm})\end{array}$ & $\begin{array}{c}\text { Cross-sectional A } \\
\left(\mathrm{m}^{2}\right)\end{array}$ & $\begin{array}{c}\text { Surface Area } \\
\left(\mathrm{m}^{2}\right)\end{array}$ \\
\hline 24.7 & 8 & 0.2402 & 161.15 \\
22.4 & 9 & 0.2670 & 160.93 \\
23.9 & 10 & 0.2906 & 160.81 \\
23.4 & 11 & 0.3129 & 160.49 \\
\hline
\end{tabular}

Note: Both areas are for the 387 tubes and not individual ones.

\section{Discussion}

\subsection{Mathematical model}

The optimum dimensions for the elliptical profile were selected as $22.4 \mathrm{~mm}$ and $9.0 \mathrm{~mm}$ for the major and minor axis respectively. This is because the surface area was considerably increased while the change in cross-sectional area was minimal. The surface area of the condenser tubes was initially $130.57 \mathrm{~m}^{2}$ but with the new elliptical profile, the surface area increased by $23.1 \%$ to $160.1 \mathrm{~m}^{2}$. Conversely, the cross-sectional area changed by $0.72 \%$. The dimensions were obtained while assuming a $15 \%$ increase in the rate of heat transfer as shown earlier in the calculations. An increased rate of heat transfer would necessitate a larger cross-sectional area. Meanwhile, a smaller increase in the rate of heat transfer would not justify the implementation of the configuration. Therefore, a $15 \%$ increase in the value of $\dot{Q}$ was selected as the ideal and optimum option.

Originally, the seawater outlet temperature was $328.3 \mathrm{~K}$, whereas the employment of elliptical tubes raised the value to $328.8 \mathrm{~K}$, i.e. a $0.5 \mathrm{~K}$ increase. However, this slight increase for a large scale desalination process, running continuously is indeed a substantial enhancement to the current design.

\subsection{CFD Data and results}

Fig. 4 shows the temperature contour of the seawater as it flows through the condenser tubes. It illustrates the original/current situation at the desalination plant. However, fig. 5 shows the temperature contour for the elliptical tubes arrangement with the preferred $[22.4,9.0] \mathrm{mm}$ dimensions. An apparent improvement can easily be noticed by the red temperature contour towards the tubes outlets. This signifies that the temperature of the seawater outlet has indeed increased to $328.8 \mathrm{~K}$ from the original $325 \mathrm{~K}$, as established via the mathematical model. 


\subsection{Data analysis and results validation}

In order to verify and validate the CFD analysis obtained by the surface integrals feature in ANSYS FLUENT 12.1, the results were compared directly to the mathematical model. In both cases, the seawater outlet temperature was determined to be $328.8 \mathrm{~K}$.

\subsection{Design implementation}

An increased rate of heat transfer will preheat the flowing seawater further in the condenser tubes. With the existing design, the temperature of seawater entering the brine heater is $103.8^{\circ} \mathrm{C}$, with a mean rise of $3.23 \mathrm{~K}$ across the stages. Employing elliptical tubes improved the mean temperature rise to $3.73 \mathrm{~K}$. Therefore, the proposed new temperature of the seawater entering the brine heater, by scaling the results along the $16 \mathrm{MSF}$ stages, will be $111.68^{\circ} \mathrm{C}$, which is greater than the Top Brine Temperature (TBT) at the Jebel Ali Desalination Plant $\left(110^{\circ} \mathrm{C}\right)$. However, this does not imply that a brine heater is not required since there will be heat losses in the tubes. But it can be deduced that the thermal energy required in the brine heater can be reduced to achieve the TBT. On the contrary, TBT can also be increased to allow additional stages for newer designed MSF units. With reference to table 4, the original thermal efficiency of the cycle is calculated as $77.7 \%$. The proposed $15 \%$ increase in $\dot{Q}$ will as a result increase the value of the 'product' by the same margin to be $318046998 \mathrm{~kJ} / \mathrm{hr}$. Therefore, the total heat output will be $1780034027 \mathrm{~kJ} / \mathrm{hr}$ resulting in an increase of $80 \%$ in the thermal efficiency of the cycle. In order to achieve the new heat output, with the existing efficiency $(77.7 \%), 2290906084 \mathrm{~kJ} / \mathrm{hr}$ of heat input would be required. The difference between the potential and current heat input yields to energy savings of $5494408 \mathrm{KJ} / \mathrm{hr}$.

\section{Conclusion}

Desalination is extremely vital for the sustainable growth of the UAE. Design of the Jebel Ali Desalination Plant can be optimized by employing elliptical condenser tubes rather than the conventional circular ones. Due to the larger surface to cross-section area ratio offered, the outlet seawater temperature is raised by $0.5^{\circ} \mathrm{C}$ across each MSF stage. The temperature rise is then scaled across the 16 stages of the MSF unit. Thus, the amount of energy required in the brine heater, to obtain the Top Brine Temperature (TBT), is subsequently reduced. The optimum dimensions for the elliptical profile are calculated to be $(22.4,9.0) \mathrm{mm}$ as validated and verified using mathematical and CFD models. This technique can potentially increase the thermal efficiency of the MSF cycle from the current $77.7 \%$ to approximately $80 \%$ resulting in energy savings of $54294408 \mathrm{~kJ} / \mathrm{hr}$. 


\section{Subscripts}

$\begin{array}{ll}1 & \text { inlet temperature } \\ 2 & \text { outlet temperature } \\ \text { c } & \text { circular tubes } \\ \text { ci } & \text { cold water inlet } \\ \text { co } & \text { cold water outlet } \\ \text { e } & \text { elliptical tubes } \\ \text { hi } & \text { hot vapour inlet } \\ \text { ho } & \text { hot vapour outlet } \\ \text { lm } & \text { log mean temperature difference }\end{array}$

\section{References}

[1] Akili D. K. et al., Advances in seawater desalination technologies, SaudiArabia: Elsevier, 221, pp. 47-69, 2008.

[2] Sommariva, C. and Syambabu, V.S.N., Increase in water production in $U A E$, Abu Dhabi : Elsevier, 2001.

[3] Dasari, S.,UAE focuses on technology to meet rising water emand,Business, 24-7, [Online] November 8, 2009.

[4] Anglin, M.R. How Does Desalination Work? Wise Geek, [Online] 2009.

[5] Shoaiba Desalination Plant - Water Desalination. Water-technology. [Online] http://www.water-technology.net/projects/shuaiba/.

[6] EL-Dessouky, H. et al., Analysis of Multistage Flash Desalination Flashing Chambers, Kuwait City : IChemE, 2004.

[7] El-Dessouky, H. et al., Multi-stage Flash desalination: present and futture Outlook, Kuwait : Elsevier, 1999.

[8] Helal, A.M. et al., Economic feasibility of alternative designs of a PV-RO desalination unit for remote areas in the United Arab Emirates". Abu Dhabi: Elsevier, 221, pp. 1-16,2008.

[9] Helal, A.M., and A1-Malek, S.A., Design of a solar-assisted mechanical Vapor compression (MVC) desalination unit for remote areas in the UAE, Abu Dhabi : Elsevier, 197, pp. 273-300, 2006.

[10] Helal, A.M., and Odeh, M., The once-through MSF design, Feasibility for future large, Abu Dhabi : Elsevier, 166, pp. 25-39, 2004.

[11] El-Naas, M.H. et al., A combined approach for the management of desal. reject brine and capture of $\mathrm{CO}_{2}$. Al Ain: Elsevier, 251, pp. 70-74, 2010.

[12] Mohameda, A.M.O. et al., Impact of land disposal of reject brine from desalination plants on soil and groundwater. Al Ain: Elsevier, 182, pp. 411-433, 2005.

[13] Cengel, Y.A., Turner, R.H., and Cimbala, A.M., Fundamentals of Thermo- Fluid Sciences, New York: McGraw-Hill, ISBN 978-007126631-4, 2008.

[14] Kalendar, A.Y. and Griffiths, A.J., Performance study of enhanced and smooth surface tubes in a system condenser of a multistage flash desalination unit, Kuwait : Elsevier, 134, pp. 269-283, 2001. 